\title{
Tax Day - día de la declaración jurada tributaria en los Estados Unidos de América y en la República Argentina
}

POR MÓNICA BARIGGI(*)

\begin{abstract}
Sumario: I. Introducción.- II. Declaración jurada tributaria y el Tax Day.- III. El impuesto a las ganancias/renta en Estados Unidos de América y el origen del día del tributo o Tax Day.- IV. Tax Day - el día de presentación de la declaración jurada tributaria en los Estados Unidos de América.- V. El Tax Day en Argentina.- VI. Origen del impuesto a las ganancias/renta en Argentina.- VII. El día de presentación de la declaración jurada del impuesto a las ganancias.VIII. Conclusión.- IX. Bibliografía.
\end{abstract}

Resumen: en Estados Unidos de América acontece un gran evento que enmarca la presentación de información tributaria respecto del impuesto a las ganancias ante el fisco, llamado y reconocido como Tax Day. En nuestro país existe el mismo acto tributario para el mismo tipo de impuesto, sin embargo, la importancia de la fecha límite del día de la presentación de la declaración jurada del impuesto a las ganancias no se observa con las mismas características. Del análisis del Tax Day, sus orígenes y características, como así también de la identificación de las diferencias y similitudes con la norma argentina se pretenderá dar respuesta a por qué resulta ser tan importante en ese Estado este instituto.

Palabras claves: Tax Day - declaración jurada tributaria - día del tributo impuestos directos - impuesto a las ganancias

(*) Prof. Adjunta interina de Finanzas y Derecho Financiero, Cátedra 3, Facultad de Ciencias Jurídicas y Sociales, Universidad Nacional de La Plata (UNLP). 


\title{
Tax Day - the day when income tax returns are filed in the United States of America and Argentine Republic.
}

\begin{abstract}
United States of America there is an event of significant importance when income tax returns are filed before the IRS known as Tax Day. In our country there is the same tax event for the same type of tax, however, the significance of the deadline to file income tax returns does not share the same characteristics. From the analysis of the Tax Day, its origins, characteristics as well as its differences and similarities with Argentine Law, this paper will intend to explain why it is so important in America.
\end{abstract}

Keywords: Tax Day - tax returns filed - direct taxes - income tax.

\section{Introducción}

Año tras año, en las proximidades del mes de marzo puede leerse, tanto en los medios locales de Estados Unidos de América como en los internacionales, el gran evento de relevancia local que enmarca la presentación de información tributaria ante el fisco, llamado y reconocido internacionalmente como Tax Day o el día del tributo. Dicho evento reside en una obligación de accionar por parte del residente de dicho país para con el Estado, implica un acto de ciudadanía, consiste en el plazo máximo que el fisco otorga para la presentación de la declaración jurada del impuesto a los réditos o ganancias.

Es seguro que la importancia no surge sólo de una buena publicidad o acto de propaganda por parte del ente recaudador, sino que la relevancia que adquiere este acto tributario en el país mencionado tiene su respuesta en otros factores más profundos y complejos, los cuales se pretenden analizar, revelando que uno de esos factores se encuentra relacionado con la historia del tributo donde se encuentra esta obligación de presentación de declaración jurada, y otro de los factores reside en el tipo de norma de creación de ese tributo, que, al mismo tiempo, en su evolución normativa terminó fijando el Tax Day.

En nuestro país existe el mismo acto tributario para el mismo tipo de impuesto; sin embargo, la importancia de la fecha límite del día de la presentación de la declaración jurada del impuesto a las ganancias no se presenta en ninguna jurisdicción tributaria con las mismas características reseñadas ut supra, en tanto en nuestro país resulta ser realmente una carga tributaria y no un gran evento de la ciudadanía.

Por tal motivo, el objetivo del análisis se encuentra centrado en comparar las legislaciones de ambos países, no solo en relación a las características del instituto Tax Day como declaración jurada tributaria del impuesto a las ganancias/renta 
en el cual se encuentra inmerso, sino también la evolución histórica que dicho tributo tuvo tanto en Estados Unidos de América como en la República Argentina.

En este sentido, a fin de llevar a cabo el objetivo planteado, se abordará el análisis de aquellas aristas vinculadas a las características del tributo en cada país, teniendo en cuenta también su norma de creación para poder, de esta forma, estudiar la influencia - relevante o no- que tiene en ellos el Tax Day, para luego terminar con el análisis del procedimiento tributario de la declaración jurada que cada jurisdicción planifica para dicho acto tributario, abordando así un escenario comparativo lo más acabado posible del mismo instituto en ambas jurisdicciones.

Consecuentemente, se pretenderá dar respuesta a los interrogantes por qué resulta ser tan importante en Estados Unidos de América la referida figura y cómo repercute un instituto de similares características en jurisdicciones en donde algunas características vinculadas a su origen y norma de creación no coinciden con las de ese país.

\section{Declaración jurada tributaria y el Tax Day}

A fin de otorgar una primera aproximación al análisis del fenómeno del Tax Day en los Estados Unidos de América, debe adelantarse que, en principio, la actividad desarrollada en el mismo es la de una determinación tributaria.

En tal marco, debe recordarse que la determinación de la obligación tributaria implica una actividad, ya sea por parte del Estado, ya sea por parte del sujeto obligado al pago, mediante la cual se establece un acto o conjunto de ellos destinados a brindar información y recolectar, verificar y controlar elementos, datos y circunstancias de hecho, derecho y económicas, mediante los que se puede alcanzar a plasmar una situación tributaria concreta, detallada y específica, visualizando asimismo la cuantificación de obligación de pago.

En este orden de ideas, la determinación de la obligación tributaria por el sujeto pasivo resulta ser un acto efectuado por el propio contribuyente por el que reconoce una situación tributaria determinada declarándola ante el fisco.

Ahora bien, si la actividad declarativa que aquí se analiza fue cumplida con exactitud ante la IRS (administración tributaria) por el sujeto pasivo, el nacimiento, la determinación y la extinción de la obligación tributaria se cumplirán como una actividad exclusiva del sujeto pasivo, sin interferencia alguna del sujeto activo; este deber formal cumplido debidamente por el sujeto pasivo evita el uso de la potestad del organismo recaudador de proceder a la llamada determinación de oficio (recuperado de https://www.irs.gov/). 
En definitiva y más allá de las diferentes posiciones que surgen de la profundización del análisis de este instituto, la autoliquidación, autodeterminación o determinación por sujeto pasivo en Estados Unidos de América resulta como consecuencia de la imposición de un deber formal establecido por las normas tributarias a cargo del sujeto pasivo, quien debe a tal efecto seguir los procedimientos precisos indicados en la legislación tributaria en forma forzosa, por lo que debe observárselo al menos como un acto jurídico, que por sus características de declaración jurada hace responsable al declarante de su contenido, pudiendo el fisco a posteriori corroborar la exactitud de lo allí expresado (recuperado de https:// www.irs.gov/).

Consecuentemente, del resultado de la confección de la declaración jurada puede devenir o no la obligación sustancial de pago, ello así dependiendo si de la información aportada al fisco se generen saldos a favor de la administración. En este último caso generalmente se establece que la presentación del deber formal se realice conjuntamente con la satisfacción del deber de pago y a esto no escapan los preceptos tributarios del país bajo análisis.

Es entonces que la declaración jurada tributaria - en sus modalidades de presentación papel o web- que prevé los Estados Unidos de América resulta ser la materialización de la determinación efectuada por el sujeto de iure de la obligación tributaria. Así, la forma y el plazo de presentación de este instrumento está dispuesta por el fisco; la no presentación, en los modos y tiempos apropiados, derivará en consecuencias negativas tales como sanciones por incumplimiento a deberes formales o el nacimiento y cómputo de intereses y accesorios, entre otras tantas consecuencias en detrimento del contribuyente (recuperado de https:// www.irs.gov/).

En este sentido, la norma en la respectiva jurisdicción será la encargada de establecer el modo de tal determinación y el tiempo de la presentación. A fin de determinar el plazo, muchos fiscos establecen una norma llamada "calendario fiscal" o "calendario tributario", en la que en forma organizada, clara y anticipada, el contribuyente y demás responsables tributarios tendrán los vencimientos de los respectivos gravámenes. En los Estados Unidos de América, la fecha está estipulada en una norma suprema y el día del vencimiento de la presentación de la declaración jurada se lo llama Tax Day, representando tal día el plazo máximo para la presentación de tal obligación formal, siendo estipulado en anual.

Tanto la presentación en el tiempo estipulado por la norma, como - de corresponder- el pago efectuado en el plazo determinado resultan ser obligaciones legales para el cumplimiento de la obligación tributaria y la satisfacción de los recursos tributarios a favor del fisco, más allá de la posterior potestad que detente el Estado de analizar, verificar y fiscalizar al obligado de iure, en tanto que 
de proceder las devoluciones que puedan generarse a raíz de tal presentación, se efectuarán por la IRS con posterioridad a la fecha de presentación (recuperado de https://www.irs.gov/).

En definitiva, las características del Tax Day son:

\section{Cuadro No 1}

1-Cumplimiento de deber formal.

2-Presentación de declaración jurada anual.

3-Determinación de la obligación tributaria por sujeto pasivo.

4-Puede aparejar cumplimiento de obligación de pago o deber sustancial.

5-Obligación formal que obliga al sujeto pasivo.

6-Obligación que se cumplimenta web o escrito en la forma indicada por fisco.

7-Devoluciones por parte del fisco acaecen (de corresponder) con posterioridad a dicha fecha.

8-Límite temporal máximo para el cumplimiento del deber formal.

Fuente: elaboración propia en base a datos oficiales publicados por IRS. Recuperado de https:// www.irs.gov/

\section{El impuesto a las ganancias / renta en Estados Unidos de América y el origen del día del tributo o Tax Day}

Concretamente, el planteo efectuado ut supra acaece en Estados Unidos de América, en donde si bien en algunas jurisdicciones la magnitud o importancia que adquiere puede ser concordante con alguna celebración que dé lugar a día feriado, lo cierto es que el Tax Day no resulta ser un día no laborable, sino que corresponde llamar así a la fecha en que las personas humanas tienen la obligación legal de presentar su declaración jurada anual, correspondiente al impuesto a la renta - tributo similar al impuesto a las ganancias en la República Argentina-.

Luego de analizar este mecanismo se podrá dilucidar el porqué de la importancia que este día posee sobre los ciudadanos y extranjeros que obtengan rentas provenientes de los Estados Unidos de América.

Para ello es necesario recordar que el origen del ritual anual que aparece en las primeras semanas del mes de abril de cada año está relacionado con la enmienda constitucional 16, aprobada por el Congreso de los Estados Unidos de América el día 2 de julio del año 1909 y ratificada el 3 de febrero del año 1913 (Terrel, 2012).

La fecha de vencimiento vinculada al mes de abril de cada año se debe a que el Congreso, luego de la ratificación de la enmienda 16 en el año 1913, dispuso que 
la fecha límite de presentación de las declaraciones juradas tributarias fuera el día 1 de marzo (Terrel, 2012).

Posteriormente, en el año 1918, el Congreso adelantó la fecha de presentación de la declaración jurada bajo estudio para el 15 de mayo, fecha en donde permaneció hasta el año 1954.

Luego de ello, en 1954, la fecha se adelantó para el 15 de abril de cada año, dando así el sustento de por qué las fechas resultan ser coincidentes año tras año (Terrel, 2012). Es decir, que lejos de lo que acontece en institutos de similar naturaleza en la República Argentina, en donde las declaraciones juradas son fijadas año a año por el calendario fiscal de la jurisdicción recaudatoria que se trate el tributo, utilizando a tal fin normas inferiores a ley tales como disposiciones o resoluciones, en los Estados Unidos de América la fecha máxima de la presentación de la declaración jurada del impuesto a la renta fue establecida bajo fundamentos constitucionales por el Congreso y esta es una diferencia sustancial en la que se sostiene la importancia que adquiere el Tax Day.

Pero la relevancia del instituto bajo análisis no surge exclusivamente de la clase de norma en la que se sustenta su creación, sino que también se debe a una serie de eventos históricos concatenados, ya que la creación de la enmienda 16 y la consecuente incorporación de la fecha del Tax Day proviene de la previa a la aprobación y ratificación de la misma que surge con motivo de la necesidad de financiamiento de la guerra civil que ese país estaba atravesando.

Así las cosas, el primer pie en este análisis debe ponerse en la necesidad de la creación de la Ley de recursos (Revenue Act) del año 1861, la cual incluyó la incorporación de impuesto a las ganancias (rentas) sobre las personas humanas con el objeto de pagar los gastos de la guerra mencionada ut supra. Posteriormente, en el año 1872, el tributo fue derogado. Sin embargo, en el año 1894 el Congreso promulgó un impuesto federal sobre la renta (Terrel, 2012).

Ahora bien, luego de la creación del impuesto a las ganancias, en el año 1895, la Corte Suprema de los Estados Unidos declaró este tributo inconstitucional, en razón de que, al ser un impuesto directo, no se prorrateaba según la población de cada Estado. La creación de la enmienda 16 vino a solucionar esta objeción al permitir al gobierno federal gravar los ingresos de los individuos sin tener en cuenta la población de cada Estado (Terrel, 2012).

Habiendo dado una breve introducción a la compleja problemática histórica, corresponde ahora analizar acabadamente esta serie de eventos que se sucedieron desencadenando la solución de la creación de la enmienda 16. 
TAX DAY - DÍA DE LA DECLARACIÓN JURADA TRIBUTARIA EN LOS ESTADOS UNIDOS DE AMÉRICA Y eN la República Argentina - Mónica Bariggi (PP. 311-334)

\section{III.1. La Ley de recursos de 1861 (Revenue Act, 1861) y la Ley de tarifas de 1894 (Wilson Gorman Act, 1894)}

La redacción de la Ley de recursos de 1861 (ley de fecha 5 agosto del año 1861, Cap. XLV, 12 Stat. 292) generó la primera norma de creación del impuesto a las ganancias de Estados Unidos de América.

Tal como fuera mencionado, la ley guarda su fundamento en la necesidad de financiar la guerra civil que se extendió desde el año 1861 al 1865. En este contexto, el tributo se diseñó teniendo en cuenta la renta anual de cada persona residente en Estados Unidos de América, ya sea que la renta fuera proveniente de cualquier propiedad, profesión, empleo o de cualquier otro origen, llevada a cabo en el territorio de los Estados Unidos, estableciéndose asimismo una alícuota fija estimada en la ley del 3\% con un mínimo de no imposición de $\$ 800$.

Las disposiciones del impuesto a las ganancias establecidas en las secciones 49, 50 y 51 de la ley bajo análisis, fueron derogadas por la Ley de recursos del año 1862 (sección 89). La misma reemplazó la alícuota fija que hasta el momento tenía, por la incorporación de una escala progresiva que fluctuaba desde el 3\% de la renta anual y el $5 \%$ sobre la renta por sobre los $\$ 10.000$ o para aquellos que vivan fuera del territorio de los Estados Unidos de América, previendo asimismo la finalización del tributo en el año 1866.

Sin embargo, debe señalarse que la Ley de recursos de 1861 no solo creo el impuesto a las ganancias, sino que impuso varios aranceles a las importaciones, incluyendo bienes tales como azúcar, te, nueces, azufre, café, licor, frutas y hierbas. Así, la mayoría de las importaciones fueron gravadas con impuestos por unidad de medida (llamada también base imponible específica), mientras que otras fueron establecidas con una base imponible ad valorem (valor de mercadería en aduana), como lo fue para productos como pieles, cítricos, sedas y pólvora; en tanto que estas últimas se constituían en el mercado internacional con precios más variables. Finalmente, las alícuotas variaban desde el $10 \%$ al 50\% para bienes como los vinos.

En este orden, la ley del año 1861 estableció un tributo adicional con una alícuota del $10 \%$ sobre la base imponible ad valorem a los artículos importados provenientes de embarcaciones extranjeras cuyo origen fuera más allá del Cabo de Buena Esperanza, ampliando así la protección tributaria establida por el Arancel de Morril de 1861.

Respecto al impuesto a la propiedad, la ley bajo análisis instituyó un tributo a la propiedad inmobiliaria elaborado en proporción a la población de cada Estado, fijando alícuotas mayores a los estados con mayor densidad demográfica. 
Es decir, que la Ley de recursos de 1861 no se limitó a legislar sobre el impuesto a las ganancias aumentando la alícuota, sino que avanzó sobre otras situaciones gravables como impuestos a la propiedad y tributos aduaneros (en especial los derechos a la importación); todo ello con el objeto de hacer frente al financiamiento del Estado Federal, que resultaba necesario y urgente solventar en ese momento.

Finalmente, en el año 1894 se sanciona la Ley de aranceles o la llamada Ley Wilson Gorman (nombrada así por dos de los congresistas que impulsaron la norma), creada en el marco de la crisis económica de 1893 de los Estados Unidos de América.

El objetivo de esta norma de aranceles fue la recuperación económica en base a dos pilares centrales de acción: por un lado, reducir los aranceles de los tributos aduaneros, con la finalidad de abrir mercados al extranjero para los productos estadounidenses y, por otro lado, se buscó la creación del impuesto federal sobre la renta, en tanto que dicha norma reducía los tributos aduaneros de donde provenían la mayor parte de los recursos del Estado - esto es, los tributos a la importación-, por lo que el Congreso entendió que el lugar de donde buscar recursos públicos correspondía ser los tributos directos.

Debe adelantarse que ninguno de estos objetivos fue alcanzado positivamente: la reducción de los tributos a la importación no produjo la apertura de mercados buscada sino todo lo contrario, se profundizó la entrada de productos del extranjero que atentaba contra la producción local y el tributo a la renta instaurado provocó resistencia entre los sectores más productivos y ricos, hasta la sentencia del fallo en el caso Pollock, acción judicial que se impuso en base a la resistencia que existía contra el tributo.

\section{III.2. El caso "Pollock" y la solución de la enmienda 16}

Tal como fuera adelantado en los párrafos que preceden, resulta necesario explicar algunos aspectos de la problemática que se presentó con el caso judicial Pollock vs. Farmes Loan \& Trust Co., en tanto la decisión judicial que se analizara fue rebatida finalmente por otro remedio jurídico, generando la creación de la enmienda 16, que rige en la actualidad y le otorga las características finales al instituto bajo estudio.

Este decisorio judicial se originó con motivo de la creación, en el año 1894, de una ley mediante la cual el Congreso estableció durante un período de cinco años que las empresas serían gravadas un $2 \%$ en sus ganancias netas.

Consecuentemente con lo expuesto y en cumplimiento de esa ley, la sociedad de inversiones de los agricultores del estado de Nueva York — quien fuera también 
demandada en este fallo que se analiza-informó a sus accionistas que retendría esa suma de los dividendos y que remitiría al Departamento del Tesoro la lista de sus inversionistas obligados al pago del tributo.

Así las cosas, Pollock, como accionista de la sociedad, inició una acción judicial solicitando la declaración de la inconstitucionalidad de la ley, en tanto alegó que en la norma se establecía de manera irregular un impuesto directo que no respetaba la Constitución de los Estados Unidos, al disponerse allí que los impuestos directos se prorratearán entre los distintos Estados que formen parte de esa Unión, de acuerdo con su población respectiva (artículo I, $2^{\mathrm{a}}$ sección, cláusula $3^{\mathrm{a}}$ ).

En la resolución de este caso judicial llevado al más alto tribunal de justicia de Estados Unidos de América, en una votación dividida de 5 a 4 jueces se consideró procedente revocar la sentencia de la instancia anterior que no había hecho lugar a la demanda de Pollock, entendiendo que los impuestos sobre la renta constituyen impuestos indirectos regulados por el artículo I, $8^{\text {a }}$ sección, cláusula $1^{\text {a }}$ de la Constitución, que prevé que el Congreso de ese país tiene facultad para establecer y recaudar contribuciones, impuestos, derechos y consumos. Sin embargo, precisó dicho Tribunal que el impuesto a los dividendos y las rentas establecido por la ley de 1894, impugnada por Pollock, impactaba de manera decisiva en los activos subyacentes, de manera tal que correspondía considerarlo un impuesto directo y por lo tanto sujeto a la regla del prorrateo entre estados establecida por el artículo 1, 2 $2^{\text {a }}$ sección, cláusula $3^{\text {a }}$ de la Constitución Federal.

Resulta de vital importancia advertir que este problema surgió en atención a que el Congreso creó el impuesto a la renta como reacción contra los impuestos al consumo, que habían financiado hasta ese momento al gobierno federal durante la mayor parte de su historia, generando una sobrecarga a las personas de bajos ingresos, por lo que el impuesto a la renta intentaba diseñarse con miras de llegar a los sectores de más altos ingresos, cuya renta provenía de inversiones y que por tanto podían responder con su capacidad contributiva más amplia.

Cabe resaltar que al momento de la resolución del caso bajo estudio ya existían otros casos judiciales, como Hylton y Springer (que abajo brevemente se explican), en los que algunos consideraban que el impuesto a la renta era un impuesto directo que debía ser prorrateado, pero sin ser esta tesitura sustentada por todos los juristas, ni mucho menos el marco doctrinario conceptual claro; ello, en tanto no quedaban sentadas las características para el prorrateo; sin embargo, el Tribunal Superior - en el fallo Pollock - innovó al concluir de manera categórica y sin dar lugar a duda alguna en que el impuesto a la renta era un impuesto directo y, por lo tanto, tendría que ser prorrateado conforme a las pautas constitucionales reseñadas. 
En este sentido, la Corte razonó que gravar los ingresos de la propiedad era equivalente a gravar la propiedad en sí. Debe destacarse que el tribunal que se expresó en el caso Pollock fue un tribunal que algunos endilgaron como conservador y desconfiado, por lo que argumentaron que consistía en un ataque a la capital, una discriminación arbitraria entre aquellos que reciben un ingreso de $\$ 4,000$ y aquellos que no lo hacen.

Sin embargo, en el año 1913, la 16 a enmienda a la Constitución Federal estableció, en sentido inverso al precedente Pollock, que el Congreso tendrá facultades para establecer y recaudar impuestos sobre los ingresos, sea cual fuere la fuente de que provengan, sin prorratearlos entre los diferentes Estados en razón de ningún censo o recuento.

Es así que la enmienda constitucional 16 llegó y se impuso con el objeto de cumplir un rol central en la construcción de la distribución tributaria de los Estados Unidos de América, en tanto hizo posible la instauración del —por entonces novedoso- impuesto a la renta a nivel nacional, intentando solucionar las disputas económicas, jurídico-judiciales que se habían presentado hasta el momento. Ante tal modificación normativa, el impuesto a la renta se convirtió para el gobierno federal en la más importante fuente de recursos públicos del Estado, sosteniéndose tal situación en la actualidad conjuntamente con los tributos federales vinculados a la seguridad social. No es menor resaltar que la enmienda mencionada fue parte de una corriente de enmiendas constitucionales incorporada en el siglo XX, revirtiendo el fallo de la Corte de 1895.

En este contexto, debe entenderse que la cláusula tributaria de la Constitución citada en el artículo 1 Sección 8 otorga al Congreso el amplio poder para establecer y recaudar derechos, impuestos e impuestos especiales, pero el artículo mencionado también establece que un impuesto directo debe distribuirse entre los Estados sobre la base de la población. Esto significa que, si un impuesto es llamado directo, un Estado con la décima parte de la población nacional debe asumir una décima parte de la responsabilidad total sin importar cuanta riqueza se produzca en esta jurisdicción, situación que genera que este tipo de tributos sean negativos en los efectos que produce.

Ahora bien, para los llamados tributos indirectos, no existe esta regla de proporcionalidad o prorrateo, ya que la Constitución sólo exige que todos los derechos, impuestos e impuestos especiales sean establecidos en forma uniforme en todo el territorio de los Estados Unidos, siendo para muchos un requisito que implica que los tributos de esta clase no puedan tener alícuotas distintas de un Estado a otro. En el siglo XIX, la mayor parte de los ingresos del gobierno provinieron de tributos al consumo sobre diversos bienes y en tal sentido la distinción de impuesto directo e indirecto era de vital importancia. 
Bajo la legislación tributaria de los Estados Unidos, un impuesto directo incluye capitaciones -mencionadas específicamente en la Constitución y generalmente entendidas como impuestos principales de suma global, esto es cada persona paga lo mismo-y también impuestos que recaen sobre la tierra. El sector de producción vinculado al campo sostenía que estos eran directos y, en tal sentido se convirtieron en los fundamentos de los agravios de sus acciones judiciales.

Un fallo previo a lo que se viene analizando fue emitido por la Corte Suprema en el caso Hylton v. United States, del año 1796, en el que se aprobó un impuesto no proporcional sobre los automotores; el contexto económico tributario versaba en que el actor poseía más de 125 vehículos para el trasporte de personas y la Corte determinó que todos los impuestos sobre gastos o consumo son impuestos indirectos, un impuesto sobre los automotores no es un impuesto directo, agregando que los impuestos indirectos son modos tortuosos de alcanzar los ingresos de las personas que viven de acuerdo a sus ingresos.

Ahora bien, en autos Springer vs. United States, de 1881, el actor, cuya actividad económica era vinculada a desarrollar la profesión de abogado y al mismo tiempo ser tenedor de bonos, se negó a pagar el impuesto a la renta por lo que, como consecuencia, el Gobierno Federal vendió su propiedad para hacer frente a la deuda tributaria subsistente. Springer se presentó judicialmente alegando que el impuesto bajo estudio violaba las reglas de distribución explicadas supra. Así, el tribunal concluyó que la Constitución de ese país entendió que los impuestos directos son sólo tributos de capitación, tal como se expresan en esa norma fundamental, e impuestos sobre bienes inmuebles, y que el impuesto del que se quejaba el demandante (impuesto a la renta) por error está dentro de la categoría de un impuesto especial.

Desarrollados brevemente los antecedentes judiciales sobre la clasificación de los tributos, debe decirse que la creación por el Congreso de la enmienda 16 en el año 1909 - ratificada a nivel nacional en el año 1913 - vino a solucionar la declaración de inconstitucionalidad sentada en el fallo Pollock, quedando desde entonces sentado que el impuesto a la renta no se aplica la regla de proporcionalidad y fijando el Congreso que, a los efectos de la presentación de la declaración jurada, la misma deberá presentarse ante el fisco antes del 1 de marzo de cada año.

Por lo tanto, se puede presentar la siguiente síntesis de eventos que desencadenaron el Tax Day: 


\section{Cuadro No 2}

\begin{tabular}{|l|l|}
\hline Evento significativo para el Tax Day & Lineamientos expuestos en cada evento \\
\hline 1-Constitución de EE.UU. & $\begin{array}{l}\text {-Impuestos directos: deben distribuirse entre los Es- } \\
\text { tados sobre la base de la población. Aplica regla de } \\
\text { proporcionalidad o prorrateo. } \\
\text {-Impuestos indirectos, no existe esta regla de propor- } \\
\text { cionalidad o prorrateo. }\end{array}$ \\
\hline 2-Ley de recursos, 1861 & $\begin{array}{l}\text {-Primera norma que crea la Ley del impuesto a la } \\
\text { renta (ganancias) en EE.UU.- (derogada por la Ley de } \\
\text { recursos 1862). }\end{array}$ \\
\hline 3-Ley de aranceles, 1894 & $\begin{array}{l}\text {-Establece el impuesto a la renta (luego de la } \\
\text { derogación). }\end{array}$ \\
\hline 4-Fallo Pollock & $\begin{array}{l}\text {-Define que el impuesto a la renta es un tributo } \\
\text { "directo". } \\
\text {-Debe respetar la cláusula del proporcionalidad o } \\
\text { prorrateo. } \\
\text {-Establece inconstitucionalidad el impuesto a la ren- } \\
\text { ta/ganancia de la ley de 1894. }\end{array}$ \\
\hline 5-Enmienda $16^{\circ}$ & $\begin{array}{l}\text {-Revierte consecuencias del fallo Pollock. } \\
\text {-Congreso con facultad de establecer impuesto a la } \\
\text { renta sin necesidad de la cláusula de proporcionali- } \\
\text { dad o prorrateo. } \\
\text {-Establece el Tax Day para el mes de marzo de cada } \\
\text { año. }\end{array}$ \\
\hline
\end{tabular}

Fuente: elaboración propia en base a datos de la Constitución de los Estados Unidos, Ley de recursos, 1861, Ley de aranceles, 1894, caso Pollock.

\section{Tax Day - el día de presentación de la declaración jurada tributaria en los Estados Unidos de América}

Ahora bien, conforme el desarrollo efectuado en los puntos que anteceden, resulta evidente que el Tax Day se sustenta en una enmienda constitucional emanada como resultado de un proceso de idas y vueltas respecto a la definición de las características propias del impuesto a las rentas/ganancias. La solución jurídica constitucional a la que se arriba fue el resultado, sin dubitación, de agregar en la norma fundamental preceptos claros que definan que en la clase de tributo estudiada no aplica la cláusula de proporcionalidad o prorrateo, hasta entonces requerida por la justicia. En tal sentido, la Enmienda 16 no solo estableció tal característica, sino que fue más allá y constitucionalmente dio los parámetros vinculados a la fecha en donde debía operar el Tax Day.

En este orden de ideas, la traducción de este instituto - dispuesto ahora constitucionalmente- del idioma inglés al castellano correspondería a un término similar al de "día del tributo" e implica ser el día vinculado al cumplimiento del 
deber formal de presentación de la declaración jurada tributaria, en principio, correspondiente al impuesto a la renta/ganancias, siendo el plazo máximo instituido por el fisco para el cumplimiento de tal deber formal.

Así conforme la información brindada por el fisco, una gran proporción de residentes (nacionales y extranjeros) de los Estados Unidos deben informar anualmente, mediante la presentación de declaración jurada en formato papel o soporte informático, al organismo de recaudación tributaria de ese país -Internal Revenue Service, conocido con la sigla IRS - los ingresos obtenidos en el año fiscal anterior, la información del grupo familiar, los datos vinculados a cada integrante familiar sobre la seguridad social y los gastos.

Esta obligación formal reviste la característica de ser un procedimiento rápido y simple, donde se obliga al contribuyente a presentar hasta la fecha límite del Tax Day la declaración jurada anual del impuesto a la renta.

En este orden de ideas, en el marco del diseño de este procedimiento establecido por el organismo de recaudación de ese país, el contribuyente puede optar por presentar su declaración anual formato papel, en cuyo caso deberá utilizar el formulario indicado por la IRS y remitirlo por correo a la dirección que fija la misma a tal efecto.

Asimismo, el contribuyente, de optar por efectuar la presentación de la declaración jurada online, deberá ingresar al sitio oficial indicado por la I.R.S. para que dicha presentación sea válida hasta la fecha máxima establecida por la autoridad de aplicación.

Tal como sucede en muchos procedimientos tributarios del mundo, la presentación de la declaración jurada en el Tax Day no implica la devolución o el reembolso tributario, ya que estos pueden ser consecuencia de la información que recabe el fisco con motivo de la declaración jurada presentada y de la información adicional que obtenga de otros agentes de información; sin embargo, para aquellos contribuyentes que presenten sus declaraciones juradas en forma web, el período de devolución previsto por la autoridad fiscal es más rápido (de corresponder), oscilando entre 1 mes o 3 semanas aproximadamente.

Si bien, como se adelantó ut supra, el Congreso - mediante la enmienda 16estableció la fecha máxima del pretendido Tax Day hasta el 1 de marzo, lo cierto es que anualmente el IRS abre el período de presentación de las declaraciones juradas del impuesto a la renta en el mes de enero y pone como fecha límite la establecida por la norma señalada.

Asimismo, el procedimiento prevé la posibilidad de solicitar una prórroga de la presentación de la declaración jurada, la cual deberá efectuarse formalmente y 
se concederá en forma automática por el término de 6 meses, con la posibilidad de solicitar una prórroga adicional; debe aclararse que el pedido de prórroga no interrumpe la obligación de pago, con lo cual se deberán abonar los intereses respectivos si la declaración jurada posee saldos a favor del fisco.

A continuación, se podrán observar en forma esquemática las características del procedimiento del Tax Day en Estados Unidos de América.

\section{Cuadro No 3}

\begin{tabular}{|l|l|}
\hline Contribuyente informa & $\begin{array}{l}\text { a- ingresos del período fiscal. } \\
\text { b- información del grupo familiar. } \\
\text { c- gastos del período fiscal. } \\
\text { d- información de seguridad social. }\end{array}$ \\
\hline Forma de presentación & $\begin{array}{l}\text { a- papel: se envía por correo a la dirección postal indicada por } \\
\text { la I.R.S.(opcional). } \\
\text { b- web: se ingresa al sitio indicado por la I.R.S. (opcional). } \\
\text { c- declaración jurada. }\end{array}$ \\
\hline Plazos & $\begin{array}{l}\text { - La I.R.S. abre el período de presentación desde el mes de } \\
\text { enero hasta el Tax Day, que es en el mes de marzo. } \\
\text { - Es anual. }\end{array}$ \\
\hline Solicitud de prórrogas & $\begin{array}{l}\text { Se pueden solicitar prórrogas a la IRS, de } 6 \text { meses (automáti- } \\
\text { ca) y una prórroga adicional (a solicitud de parte). }\end{array}$ \\
\hline Asesoramiento & $\begin{array}{l}\text { La IRS brinda ayuda profesional para efectuar la declaración } \\
\text { jurada. } \\
\text { Se puede recurrir a profesionales especializados. }\end{array}$ \\
\hline Devoluciones de tributo & $\begin{array}{l}\text { La devolución, de proceder, es más rápida si el contribuyente } \\
\text { utilizó la opción de presentación de declaración jurada web } \\
\text { (entre l a 3 semanas). }\end{array}$ \\
\hline Pago & $\begin{array}{l}\text { De ser procedente deberá, conjuntamente con la presenta- } \\
\text { ción de la declaración jurada, presentarse el pago del tributo. } \\
\text { El pedido de prórroga no suspende la obligación de, por lo } \\
\text { que los intereses y accesorios, de corresponder, siguen siendo } \\
\text { adeudados. }\end{array}$ \\
\hline
\end{tabular}

Fuente: elaboración propia en base a: IRS. Recuperado de https://www.irs.gov/

\section{El Tax Day en Argentina}

Entendiendo, entonces, que el instituto bajo estudio recae sobre un tributo en particular que resulta ser la obligación formal para el impuesto a las rentas/ganancias en el país del norte, debe analizarse ahora si es posible contar el desarrollo de este evento en la legislación argentina en el impuesto referido y, si la respuesta es positiva, debe analizarse si gozan ambos institutos de las mismas características.

Es así que, habiendo analizado la importancia y características del instituto en Estados Unidos de América, corresponde adelantar que en la República Argentina 
existe el Tax Day, es decir, existe el día del tributo para el impuesto a las ganancias/ renta, en donde recae el deber de la presentación de la declaración jurada tributaria del impuesto.

En términos generales, debe mencionarse que todos los tributos poseen fechas establecidas por los fiscos en donde se disponen los vencimientos de pago y los límites de presentación de las declaraciones juradas y esto incluye también al impuesto a la renta/ ganancia.

Sin embargo, claramente la importancia que recae sobre el Tax Day en los Estados Unidos de América no puede ser encontrada en la aplicación de ninguna norma argentina que disponga vencimientos tributarios. La relevancia de la fecha de vencimiento de la presentación de la declaración jurada en el impuesto a las ganancias/ renta no reviste en Argentina la característica de un acto ciudadano, no genera fechas de suspensión laboral o de actividades; no puede vislumbrarse en nuestro país para el tributo bajo estudio ni para los demás tributos la generación de un acto primordial económica, ciudadana y políticamente, sino todo lo contrario, en general, es percibido como una carga u obligación en sentido negativo para con el contribuyente y responsable obligado.

Ello, debido a que la evolución de la importancia del tributo en materia del impuesto a la renta (ni de los demás tributos) no ha generado un desarrollo histórico similar en nuestro territorio, como así tampoco el vencimiento de las obligaciones tributarias de ningún tributo ha adquirido rango constitucional como el que se ha analizado ut supra y, finalmente, tampoco puede vislumbrarse en el diseño del sistema constitucional tributario argentino el requisito de prorrateo o proporcionalidad que la norma estadounidense asignaba al impuesto a la renta por ser un tributo directo, sin mayores discusiones al respecto, y por lo tanto no genera conflictos sobre ese tema.

Esta diferenciación sustancial obliga a analizar las características de la fecha de ingreso del impuesto a las ganancias (renta) desde la óptica de la legislación local y sus consecuentes características, es decir que no se puede estar hablando del Tax Day con la importancia y relevancia que se vislumbra en Estados Unidos de América.

Sin perjuicio de lo expuesto, lo cierto es que tanto la declaración del Tax Day como la declaración jurada del impuesto a las ganancias, a pesar de no compartir el mismo origen ni recorrido en la problemática tributaria, puede adelantarse que sí comparten la misma naturaleza y características generales de ser una declaración jurada tributaria realizada por el sujeto pasivo en cumplimiento de los deberes formales impuestos por el fisco. 
En adición a lo expuesto, otra de las distinciones sustanciales que podría observarse en nuestro país referente al día de la declaración jurada en general y en particular en el impuesto a las ganancias / renta, se encuentra en el tipo de norma que la sustenta: en tal sentido, es técnica normativa usual en todos los organismos fiscales emplear una norma de tipo reglamentaria tal como disposición normativa o resolución normativa o general llamada calendario fiscal y creada a los fines de establecer cronológicamente dentro del llamado período fiscal todos los vencimientos de pago y de presentación de declaración jurada para todos los tributos de cada jurisdicción en la que se posea potestad tributaria.

Si bien no está contemplado el pedido de prórrogas por parte del contribuyente y aunque no es usual, el fisco puede conceder dichas extensiones de plazo de los vencimientos de declaración jurada de oficio. Las prórrogas, salvo situaciones especiales concretas como emergencias climáticas, económicas, etc., son efectuadas utilizando el mismo tipo de norma reglamentaria con la que fue creado el calendario fiscal para dicho período.

Respecto al resto de las características del instituto en comparación con Estados Unidos de América, se puede decir que guarda similitud en tanto se trata del cumplimiento de un deber formal impuesto por el organismo de recaudación, que consiste en la presentación de la declaración jurada en la fecha determinada por la norma establecida por la AFIP.

Dicha obligación formal debe ser cumplida en forma web por el sujeto pasivo de la obligación tributaria, aunque la declaración jurada no es privativa de ellos, en tanto que puede ser presentada por el agente de recaudación, por ejemplo, para el caso del ingreso en el impuesto a las ganancias de la renta obtenida por la cuarta categoría por parte del empleador en su carácter de agente frente al impuesto.

Finalmente, las devoluciones pueden proceder, de corresponder, con posterioridad a la presentación de la declaración jurada, como resultados de lo allí expuesto por el sujeto obligado.

Consecuentemente, a continuación se efectúa un cuadro enunciativo de las características del día de la declaración jurada argentina:

\section{Cuadro No 4}

1- Establecida en norma reglamentaria.

2- Cumplimiento de deber formal.

3- Presentación de declaración jurada anual / se pueden disponer deberes de presentación de declaración jurada mensual / bimestral / periódicas. 
4- Determinación de la obligación tributaria por sujeto pasivo (la declaración jurada puede ser presentada por agentes de recaudación conforme lo establezca el organismo de recaudación). 5- Puede aparejar cumplimiento de obligación de pago o deber sustancial. 6- Obligación formal que obliga al sujeto pasivo / agente de recaudación.

7- En el impuesto a las rentas/ganancias la obligación se cumplimenta vía web en la forma indicada por fisco.

8- Devoluciones por parte del fisco acaecen (de corresponder) con posterioridad a dicha fecha.

9- Límite temporal máximo para el cumplimiento del deber formal fijado por el calendario fiscal en norma reglamentaria establecida por el fisco.

Fuente elaboración propia en base a Ley de ganancias y datos obtenidos de la página oficial de la AFIP. Recuperado de www.afip.gov.ar

\section{Origen del impuesto a las ganancias/renta en Argentina}

Entendiendo que lo que ocurre en Estados Unidos de América se sustenta principalmente en la evolución histórica y distinción del tipo de tributo a las rentas/ganancias, cabe efectuar aquí un breve análisis del origen del impuesto a las ganancias en nuestro país, que si bien no se vincula al Tax Day, es decir, con su declaración jurada, sí encuentra una discusión respecto a los tributos directos e indirectos y la llamada división en la fuente establecida en el artículo 75 inciso 1 y 2 de la Constitución Nacional.

El impuesto a las ganancias en nuestro país resulta ser un tributo directo; por tal motivo, analizando la norma constitucional que distribuye la potestad tributaria argentina, se entiende que:

a) En forma exclusiva corresponde a la Nación la legislación respecto a tributos aduaneros (conforme artículo 75 inciso 1 Constitución Nacional —CN-).

b) En forma concurrente a la Nación y a las provincias la legislación respecto de tributos indirectos (conforme artículo 75 inciso $2 \mathrm{CN}$ ).

c) En forma exclusiva a las provincias y excepcionalmente a Nación la legislación en materia de tributos directos (conforme artículo 75 inciso $2 \mathrm{CN}$ ).

Consecuentemente, siendo el impuesto a las ganancias un tributo directo corresponde a las provincias en forma exclusiva su creación, ya que así fue expresamente establecido en la Carta Magna.

Haciendo uso de la excepcionalidad, la Nación creó —en el año 1932, publicada en el Boletín Oficial el 12 de enero del año 1933- el decreto-ley No 11682, con el carácter de impuesto de emergencia sobre los réditos (Ley del impuesto a las ganancias), vigente hasta el año 1934. El carácter de emergencia dispuesto en su 
creación y sostenido por las normas modificatorias posteriores trataban de darle sustento constitucional, en tanto que, siendo un tributo directo, la única forma de que la jurisdicción nacional pueda crearlo estaba basada en mantener la necesidad que la defensa, seguridad común y bien general del Estado lo exijan, requisito exigido por el artículo 67 inc. 2 de la Constitución Nacional vigente al momento de la creación de la ley tributaria.

La norma tuvo distintas modificaciones y prórroga de la emergencia, siendo en el año 1994 - con la reforma constitucional, artículo 75 inc. 2- cuando se faculta a la Nación para que establezca impuestos directos por tiempo determinado en todo su territorio, siempre que la defensa, seguridad común y bien general del Estado lo exijan. Así, los constituyentes en 1994 no hicieron aclaración alguna respecto a que el impuesto a los réditos/ganancias disponga de tratamiento especial en materia de potestad tributaria, por lo que desde el año 1933 el impuesto a los réditos/ganancias resulta ser un tributo directo legislado por la jurisdicción nacional por razones de emergencia, en forma temporal, en el marco de una necesidad de defensa, seguridad común y bien general, discrecionalidad sustentada hace aproximadamente 80 años.

Tal como es de observarse en nuestro país, en el origen de la creación del tributo bajo análisis también se encuentra la discusión centrada en plantear la distinción de tributos directos e indirectos; sin embargo, en la República Argentina se enfoca en sustentar quién detenta la potestad tributaria y cómo la sostiene en base a los mandatos constitucionales. Es así que este problema referido al sustento en el tiempo de los tributos directos de emergencia en mano de la jurisdicción nacional aún no ha encontrado una clara solución en la norma argentina, incluso luego de la reforma de la Carta Magna en el año 1994, manteniéndose entonces su creación en el ámbito de la jurisdicción nacional.

\section{El día de presentación de la declaración jurada del impuesto a las ganancias}

Del análisis que antecede puede desprenderse entonces que ni el origen del impuesto a las ganancias ni su evolución histórica del tributo en la jurisdicción argentina han logrado generar cambios sustanciales en el impuesto, en sus características ni en los aportes que la carta suprema hace sobre el recurso analizado; ello lo separa claramente del mismo tributo analizado en Estados Unidos de América. La evolución del tributo en esta jurisdicción no ha logrado otorgar a ninguna parte del procedimiento vinculado a su declaración e ingreso algún dote especial o importancia de relevancia tal que genere en los obligados un evento primordial de su vida ciudadana, todo lo contrario.

Sin embargo, debe adelantarse que el procedimiento argentino de presentación de la declaración jurada en el impuesto a las ganancias no dista mucho de lo que sucede con otros tributos locales e internacionales en lo que refiere a su 
presentación y pago, conforme se puede vislumbrar con el análisis comparativo que se genera a continuación.

En este sentido, conforme la Ley de ganancias de este país, sus normas reglamentarias y la información brindada por el fisco, en la jurisdicción nacional corresponde a la Administración Federal de Ingresos Públicos (AFIP) ser el organismo encargado de fijar el calendario fiscal anual. Conforme a las pautas que el organismo de recaudación, la declaración jurada del impuesto a las ganancias en la República Argentina debe ser presentada año a año por aquellos sujetos que configuren el hecho imponible del tributo en estudio, a saber:

A) Personas jurídicas.

B) Personas humanas/físicas (incluida la sociedad conyugal).

C) Sucesiones indivisas.

Ahora bien, a la hora de la confección de la declaración jurada puede requerirse de la asistencia de un profesional de las ciencias contables, dependiendo de la complejidad de la actividad económica y la renta que se pretende declarar; la asistencia del mismo no es otorgada por el fisco, motivo por el cual el declarante deberá contratar a un profesional de las ciencias contables solventado por sus propios medios, situación que no acontece con similar instituto en Estados Unidos de América, en donde se otorga asistencia presencial y online para guiar al presentante en la confección de la obligación formal.

En general, el fisco nacional fija la fecha de presentación de la declaración jurada sin exceder el primer semestre del año inmediato posterior al período fiscal declarado, siendo usualmente el mes de abril, en el plazo máximo fijado a tal efecto por el calendario fiscal. Dicho calendario es creado por una resolución general, esto es, una norma de menor jerarquía normativa que la utilizada en Estados Unidos de América para el mismo tributo, siendo, en consecuencia, el Tax Day el día límite de presentación de la declaración jurada que el fisco impone a los contribuyentes mencionados.

Sin embargo, el diseño procedimental dispuesto por el fisco permite, en cumplimento de los deberes de información, presentaciones de declaración jurada previa a la declaración jurada anual en situaciones especiales. Por ejemplo, aquellas personas humanas / físicas que sufran retenciones de ganancias por la renta del trabajo en relación de dependencia pueden presentar, previo a la declaración jurada anual, su declaración de deducciones personales a imputar en las rentas de la cuarta categoría, haciendo este impuesto mucho más complejo en su aplicación que el sistema que se plantea en Estados Unidos de América, en donde se presenta un solo momento de presentación de declaración jurada anual y un sistema 
de devoluciones posteriores bajo todos los orígenes de rentas y cualquiera sea la deducción a imputar que sólo varia en la rapidez; devolución dependiendo del sistema utilizado para la presentación del deber formal (web o papel).

Más aún, si bien en ambos procedimientos se presenta la declaración de los gastos a deducir, en el caso de la legislación argentina se planean momentos previos para efectuar declaraciones de gastos que no prevé la normativa norteamericana.

Otro punto a tener en cuenta se vincula con que en la declaración jurada de ganancias no se presentan los rendimientos correspondientes a tributos vinculados con la seguridad social, en tanto estos últimos resultan ser otra clase de tributos - contribuciones especiales previsionales-, recaudados por diversos organismos y jurisdicciones (no sólo la nacional) y corresponden ser declarados en oportunidad distinta dependiendo de su propia norma.

De lo expuesto se puede generar la siguiente esquematización del procedimiento de presentación de declaración jurada en la República Argentina correspondiente al impuesto a las ganancias.

\section{Cuadro No 5}

\begin{tabular}{|c|c|}
\hline $\begin{array}{l}\text { Contribuyente / agente de } \\
\text { recaudación informa }\end{array}$ & \begin{tabular}{|l|} 
a- ingresos del período fiscal \\
b- información del grupo familiar \\
c- deducciones del período fiscal
\end{tabular} \\
\hline Forma de presentación & $\begin{array}{l}\text { a- web } \\
\text { b- declaración jurada }\end{array}$ \\
\hline Plazos & $\begin{array}{l}\text { a- La AFIP - en el calendario fiscal- fija la fecha máxima de } \\
\text { presentación de la declaración jurada general, que no excede } \\
\text { del primer semestre del año inmediato posterior al período fis- } \\
\text { cal informado. } \\
\text { b- La AFIP también establece en el calendario fiscal la fecha } \\
\text { máxima de las presentaciones de las declaraciones juradas es- } \\
\text { peciales, como la de la cuarta categoría. } \\
\text { c- En principio anual, salvo los casos especiales. }\end{array}$ \\
\hline Solicitud de prórrogas & No se otorgan. \\
\hline Asesoramiento & $\begin{array}{l}\text { El fisco no lo otorga. El declarante puede asesorarse en forma } \\
\text { privada por un profesional contador público nacional. }\end{array}$ \\
\hline \begin{tabular}{|llll} 
Deducciones & de base $y$ \\
devoluciones
\end{tabular} & $\begin{array}{l}\text { La ley prevé las deducciones posibles y la presentación genera } \\
\text { las deducciones a la base posible. } \\
\text { Para devoluciones de los casos especiales, como por ejemplo } \\
\text { el de la } 4^{\circ} \text { categoría, las mismas no se hacen automáticamente, } \\
\text { sino que se devengan luego de la presentación de la declara- } \\
\text { ción jurada y en general en el primer trimestre del año inme- } \\
\text { diato posterior. }\end{array}$ \\
\hline
\end{tabular}




\begin{tabular}{|l|l|}
\hline Pago & $\begin{array}{l}\text { De corresponder, deberá conjuntamente con la presentación } \\
\text { de la declaración jurada presentarse el pago del tributo. } \\
\text { En casos especiales, como en los sistemas de retención del tri- } \\
\text { buto, el mismo se genera durante el acaecimiento del período } \\
\text { fiscal involucrado, recaudado por el agente. }\end{array}$ \\
\hline
\end{tabular}

Fuente: elaboración propia en base a Ley de Ganancias; página oficial de la AFIP. Recuperado de www.afip.gov.ar

\section{Conclusión}

En definitiva, la necesaria comparación del instituto del Tax Day en ambas legislaciones ha llevado a un recorrido por normas nacionales e internacionales que reflejan que, si bien se puede compartir una misma definición jurídico tributaria, el impacto del mismo en el obligado al cumplimiento del deber formal se evidencia de diferentes maneras, tal como fuera desarrollado.

Parece que la importancia del Tax Day comienza con tratar de definir la atribución de características de los impuestos directos e indirectos; en tal sentido, la historia de los Estados Unidos de América generó un ir y venir de pronunciamientos judiciales y normas de creación tributaria respecto al impuesto a las ganancias/ renta, ello así debido a que el artículo 1 sección 8 de la Constitución Nacional de ese país establecía una regla de prorrateo como criterio, que parecía contraponerse a los criterios de fundación misma de ese país.

De la evolución de los fallos analizados se puede observar que a la Corte de ese país le costó definir con certeza las características del impuesto a las ganancias hasta la llegada del fallo Pollock, pero las idas y vueltas sobre este dilema se terminan de solucionar en el momento de la creación de la enmienda 16, mediante la cual se instituyó: 1) gravar los ingresos de los individuos sin tener en cuenta la población de cada Estado (conocida como cláusula de prorrateo), 2) que se trata de un impuesto directo y 3 ) que el Estado federal lo impone y recauda conjuntamente con los tributos provenientes de la seguridad social.

Se pudo observar a lo largo de este trabajo que el devenir histórico del impuesto a las ganancias/rentas y los planteos de inconstitucionalidad analizados generaron la implementación de la fecha que en forma constitucional se establece en los Estados Unidos de América para el Tax Day, ello en todos los Estados que conforman dicho país de manera uniforme, aclarándose sin lugar a dudas que este tributo es federal y que, por tanto, las pautas formales y sustanciales se extienden para todo el territorio en forma equitativa, evitando discrecionalidades de implementación y recaudación, y sorteando las dudas sobre su creación. 
En nuestro país, si bien se observa la existencia de conflicto con la atribución de la potestad tributaria de los tributos directos como es el caso del impuesto a las ganancias y su creación por cuestiones de emergencia, prolongada desde el año 1933, esta situación no llevó a establecer con raigambre constitucional la fecha máxima de la presentación de la declaración jurada de este impuesto, sino todo lo contrario; en el caso de la República Argentina, dicho plazo límite puede ser establecido cada año por el fisco mediante norma reglamentaria inferior a ley, ya sea para este impuesto como para cualquier otro tributo en el territorio, ello así conforme al marco normativo vigente en este país.

Es decir que, en la República Argentina, el impuesto a las ganancias generó controversia en su aplicación, en tanto la discusión del sostenimiento de la potestad soberana de la jurisdicción nacional y el eterno estado de emergencia que sustenta su creación.

Debe agregarse también que, si bien en ambas legislaciones se observa que son recaudados por los organismos fiscales nacionales para el mismo tributo, los procedimientos guardan algunas diferencias, además de su norma de creación, tal como la presencia de casos especiales, la obligatoriedad de presentación web, la exclusividad de la declaración para el impuesto a las ganancias - sin permitir agregar allí la declaración de otro tributo, como es el caso de tributos de la seguridad social para Estados Unidos de América - y la falta de asesoramiento profesional contable del fisco en el procedimiento argentino. Estas diferencias tienen su origen en las particularidades propias de cada jurisdicción. Por lo tanto, la forma de definición del Tax Day surge en forma muy especial en el país bajo análisis, definiendo las características propias del Estado analizado, sin posibilidad de generar su réplica en la República Argentina.

\section{Bibliografía}

Amadeo, K. (2019). Tax freedom day and what it means to you. Recuperado de https://www.thebalance.com/what-is-tax-freedom-day-3306327 [Fecha de consulta: abril 2019].

Berenson, W. M. (2003). Tributación y Federalismo en los Estados Unidos de América: un Esquema. Barcelona: Oas General Secretariat.

Center on Budget and Policy Priorities (2019). Policy basics: where do our federal tax dollars go? Recuperado de http://www.cbpp.org/cms/index. $\mathrm{cfm} ? \mathrm{fa}=\mathrm{view} \& \mathrm{id}=1258$ [Fecha de consulta: enero 2019].

Center on Budget and Policy Priorities (2019). Policy basics: where do federal tax revenues come from? Recuperado de https://www.cbpp.org/research/federal-tax/ policy-basics-where-do-federal-tax-revenues-come-from 
Departamento del Tesoro delos Estados Unidos de América. Historia deI.R.S. Recuperado de http://www.allgov.com/departments/department-of-the-treasury/ internal-revenue-service-irs?agencyid $=7262$

Fishkin, J. R.; Forbath, W. E. y Jensen, E. M. The Sixteenth Amendment. Recuperado de https://constitutioncenter.org/interactive-constitution/amendments/ amendment-xvi

García Vizcaino, C. (2012). Derecho Tributario. Buenos Aires: Abeledo Perrot.

Giuliani Fonrouge, C. (2011). Derecho Financiero. Buenos Aires: La Ley.

I.R.S. History timeline. Recuperado de https://www.irs.gov/irs-history-timeline

I.R.S. (2019). Form 4868: Application for automatic extension for time to file U.S. individual income tax return. Recuperado de http://www.irs.gov/pub/irs-pdf/ f4868.pdf

Jarach, D. (1992). Finanzas Públicas y Derecho Tributario. Buenos Aires: Ediciones Cangallo.

Sung, J. F. (2002). Why is Tax Day april 15? Recuperado de http://money.cnn. com/magazines/fortune/fortune_archive/2002/04/15/321414/index.htm

Tax History Museum. 1866-1900: Reconstruction to the Spanish-American war. Recuperado de http://www.taxhistory.org/www/website.nsf/Web/THM1866?Open Document

Tax History Museum. 1901-1932: The income tax arrives. Recuperado de http:// www.taxhistory.org/www/website.nsf/Web/THM1901?OpenDocument

Terrel, E. (comp.) (2012). History of the US income tax. Estados Unidos: Biblioteca del Congreso de los Estados Unidos. Recuperado de https://www.loc.gov/rr/ business/hottopic/irs_history.html

\section{Jurisprudencia}

Suprema Corte de los Estados Unidos de América, Pollock c/ Farmers' Loan \& Trust Co., 08/04/1895. La Ley online: AR/JUR/3/1895.

Suprema Corte de los Estados Unidos de América. Recuperado de https://supreme.justia.com/cases/federal/us

Fecha de recepción: 12-02-2020 Fecha de aceptación: 21-07-2020 
